\title{
Efficient Tetra-Functional Electrocatalyst with Synergetic Effect of Different Active Sites for Multi-Model Energy Conversion and Storage
}

Sobia Dilpazirab, Pengju Ren, ${ }^{\mathrm{c}}$ Rongji Liu, ${ }^{\mathrm{ad}}$ Menglei Yuan, ${ }^{\mathrm{ab}}$ Muhammad Imran, ${ }^{\mathrm{e}}$ Zhanjun Liu, ${ }^{\text {bf }}$ Yongbing Xie ${ }^{\text {ab }}$, He Zhao ${ }^{\text {ab }}$, Yijun Yang, ${ }^{\mathrm{g}}$ Xi Wang, ${ }^{\mathrm{g}}$ Carsten Streb, ${ }^{\mathrm{d}}$ Guangjin Zhang *ab

${ }^{a}$ CAS Key Laboratory of Green Process and Engineering, Institute of Process Engineering, Chinese Academy of Sciences, 100190, Beijing, (P.R. China).

${ }^{b}$ Center of Materials Science and Optoeletronics Engineering, College of Chemistry and Chemical Engineering, University of Chinese Academy of Sciences, 100049, Beijing, China

'Synfuels China Technology Co. Ltd. Leyuan South Street II, No.1, Yanqi Economic Development Zone, Huairou District, Beijing 101407, China

dinstitute of Inorganic Chemistry I, Ulm University Albert-Einstein-Allee 11, D-89081 Ulm, Germany

eState Key Laboratory of Chemical Resource Engineering, Beijing Advanced Innovation Centre for Soft Matter Science and Engineering, College of Chemistry, Beijing University of Chemical Technology, Beijing, 100029, China

${ }^{\mathrm{f} C A S}$ Key Laboratory of Carbon Materials, Institute of Coal Chemistry, Chinese Academy of Sciences, Taiyuan, 030001, China

gKey Laboratory of Luminescence and Optical Information, Ministry of Education, School of Science, Beijing Jiaotong University, 100044, Beijing, PR China

E-mail: zhanggi@,ipe.ac.cn.

\section{Experimental}

Chemicals and Reagents: Cobalt Nitrate Hexahydrate $\mathrm{Co}\left(\mathrm{NO}_{3}\right)_{2}$, Nickel Nitrate Hexahydrate $\mathrm{Ni}\left(\mathrm{NO}_{3}\right)_{2}$, Dicyandiamide (DCD) 2-methylimidazole (2-MeIm) were bought from Aladdin. Pt/C (Pt nominally 40\% on high surface area carbon support) was purchased from Alfa Aesar. N, N-Dimethylformamide (DMF) and Methanol (Anhydrous) were obtained from Xilong scientific Corporation. Nafion solution (5 
wt. \% in lower aliphatic alcohols and water) was obtained from Sigma-Aldrich. All the reagents were used as received without any further purification. All solutions used for electrochemical measurements were prepared in milliQ water.

Synthesis of ZIF-67: ZIF-67 was synthesized by employing wet chemical approach. In the typical synthesis fixed amount of $\mathrm{Co}\left(\mathrm{NO}_{3}\right)_{2} \cdot 6 \mathrm{H}_{2} \mathrm{O}$ was dissolved in $10 \mathrm{ml}$ of anhydrous methanol followed by addition of imidazole solution after 30 minutes, prepared separately in methanol. The purple turbid mixture was kept stirring for four hours. ZIF-67 precipitates were collected by centrifugation and subsequent washing by methanol and water. The final product was dried at $60^{\circ} \mathrm{C}$ under vacuum.

Synthesis of Co@NC: Controlled pyrolysis of ZIF-67 at $750^{\circ} \mathrm{C}$ under dormant conditions yielded $\mathrm{Co@NC}$. Obtained Co@NC was washed with 2M HCl for 24 hours followed by washing with water and dried at dried at $60^{\circ} \mathrm{C}$ under vacuum.

Synthesis of Ni/DCD@ZIF-67: Ni/ZIF-67@DCD was synthesized by addition of a certain fixed amount of DCD to the metals precursor solution and was stirred to a clear solution. After that imidazole solution was introduced to the metal/DCD mixture. Appearance of purple color indicated the successful formation Ni/DCD modified ZIF-67 network. The resulting ternary mixture was kept stirring for four hours. Ni/DCD modified ZIF-67 was collected by centrifugation and subsequent washing by methanol and water the final product was dried at $60^{\circ} \mathrm{C}$ under vacuum.

Synthesis of NiSAs@ACNTFs: CoNi alloyed carbon nanotubes anchoring single atoms were obtained by controlled pyrolysis of Ni/DCD@ZIF-67 at $750^{\circ} \mathrm{C}$ for 2 
hours under inert conditions. Obtained black powder of NiSAs@ACNTFs was washed with $2 \mathrm{M} \mathrm{HCl}$ for 24 hours followed by washing with water and dried at dried at $60^{\circ} \mathrm{C}$ under vacuum.

\section{Evaluation of Electrocatalytic Performance}

All the electrochemical tests were experimented in three electrode system at room temperature using electrocatalytic $\mathrm{CHI} 760 \mathrm{e}$, electrochemical workstation. The catalysts inks were prepared by using fixed amount of catalyst in DMF and $0.5 \%$ nafion solution followed by ultrasonication for 30 minutes to obtain homogenous catalyst ink. All potentials used were calibrated to reversible hydrogen electrode. All LSV curves were corrected by ohmic compensation, and all current densities were calculated to the geometrical area of electrode.

For ORR the catalyst ink was dropped on a polished glassy carbon rotating ring disk electrode (RRDE) with a catalyst loading of $0.3 \mathrm{mg} \mathrm{cm} \mathrm{cm}^{-2}$ and dried at ambient conditions. Cyclic voltammetry (CV) and linear sweep voltammetry (LSV) were performed using the prepared glassy carbon electrode as working electrode while $\mathrm{Ag} / \mathrm{AgCl}$ (saturated with $3 \mathrm{M} \mathrm{KCl}$ ) and Platinum wire as reference and counter electrode respectively.0.1M KOH was used as electrolyte. For electrochemical performance in acid $\left(0.1 \mathrm{M} \mathrm{HClO}_{4}\right)$ the reference electrode was replaced by $\mathrm{Hg}$ calomel electrode. The cyclic voltammetry and RRDE were performed in both Ar and $\mathrm{O}_{2}$ saturated electrolyte while ring disk electrode (RDE) measurements were recorded under $\mathrm{O}_{2}$ saturated electrolyte at a scan rate of $10 \mathrm{mV} \mathrm{s}^{-1}$. 


\section{Calculation of electron transfer number $n$}

RDE measurements were used to calculate the electron transfer number (n) by using Koutechy-Levich (K-L) equation at various potentials. The electron transfer number per molecule (n) and \%yield of peroxide ions, were calculated by RRDE measurements

HER and OER were analysed by using same three electrode system with the difference that graphite rod was used as counter electrode for HER instead of Pt wire. The working electrodes were prepared by dropping catalyst ink on pre-treated carbon cloth (CC) and drying under ambient conditions. Electrochemical measurements for OER were recorded in $\mathrm{O}_{2}$ saturated electrolyte while for HER Ar saturated environment was used. Both HER and OER were tested under alkaline conditions using $1 \mathrm{M} \mathrm{KOH}$ and $1 \mathrm{M}$ phosphate buffer solution $(\mathrm{pH}=7)$. All potentials for OER and HER were referenced to reversible hydrogen electrode. Long term stability for both was tested using chronoamperometric technique. The electrolyte was stirred at constant speed in order to avoid accumulation of bubbles generated by evolution of $\mathrm{H}_{2}$ and $\mathrm{O}_{2}$ which may block the catalysis by covering the catalytic sites for oxygen and hydrogen production. For bifunctional oxygen electrocatalysis $0.1 \mathrm{M} \mathrm{KOH}$ was used as electrolyte and LSV was recorded using full potential range for ORR and OER. Two electrode water splitting system was assembled using the same material both as anode and cathode prepared by dropping catalyst ink on CC same as used for OER and HER. Water splitting was studied both in alkaline and neutral media. The electrolyte was saturated with ultrahigh-purity Ar for at least 30 minutes before 
analysis. The electrochemical measurements for $\mathrm{CO}_{2}$ reduction reaction $\left(\mathrm{CO}_{2} \mathrm{RR}\right)$ were performed by using (CHI660E) electrochemical workstation. The working electrode was prepared in the same manner as for OER and HER. A custom made two compartment H-cell separated completely by cationic exchange membrane (Nafion 117) was used for $\mathrm{CO}_{2} \mathrm{RR}$. The electrolyte was introduced in each compartment of H-cell. 0.5 $\mathrm{M} \mathrm{KHCO}_{3}$ was used as electrolyte for all $\mathrm{CO}_{2} \mathrm{RR}$ measurements. Saturated calomel electrode SCE and Pt wire were used as reference and counter electrode respectively. The electrolyte on cathode side was saturated with $\mathrm{CO}_{2}(>99.999 \%)$. Saturated calomel electrode (SCE) and Pt wire were used as reference and counter electrode respectively. Linear sweep voltammetry (LSV) was recorder first at a scan rate $5 \mathrm{mV} \mathrm{s}^{-1}$. The potentials were calibrated to reversible hydrogen electrode by Nernst equation. Catalytic performance tests were carried out by chronoamperometric technique run for one hour. Gas chromatograph was employed to detect gas products produced. $\mathrm{H}_{2}$ gas was detected and measured by thermal conductivity detector (TCD) while CO produced was analyzed by flame ionization detector (FID). nuclear magnetic resonance (NMR) was used to study the liquid products.

Utilizing the concentrations (in ppm) of produced gases as detected by gas chromatograph the percent faradaic efficiency $(\% \mathrm{FE})$ of $\mathrm{H}_{2}$ and $\mathrm{CO}$ were calculated

\section{Fabrication of Zinc Air Battery}

Zinc air battery was assembled using zinc anode, air cathode and a separator. The air cathode was prepared by using the as prepared NiSAs@ACNTFs while anode was 
prepared by zinc powder in $6 \mathrm{M} \mathrm{KOH}$. The catalyst loading was $6 \mathrm{mg} \mathrm{cm}^{-2}$. $\mathrm{Cu}$ sheet and $\mathrm{Ni}$ foam were used as current collector while Nylon filter was used as separator. A 1:1 mixture of $20 \% \mathrm{Pt} / \mathrm{C}$ and $\mathrm{IrO}_{2}$ was used for comparison.

\section{Structural Characterization}

Powder X-ray diffraction (PXRD) patterns were recorded by X'Pert PRO PANalytical diffractometer operating at $40 \mathrm{kV}$ and $30 \mathrm{~mA}$ with $\mathrm{Cu} \mathrm{K \alpha l}$ as radiation source $(\lambda=$ $0.15418 \mathrm{~nm}$ ). Scanning electron microscopy (SEM) was carried out with JOEL JSM-7610F microscope. The transmission electron microscopy (TEM) images were obtained by field-emission JEM-2100F microscope at an operating voltage of $200 \mathrm{kV}$. X-ray photoelectron spectroscopy was carried out for the elemental analysis of the samples (ESCALab220i-XL). Nitrogen adsorption-desorption isotherms were measured at $77 \mathrm{~K}$ (Autosorb-IQ, quantachrome). Brunauer-Emmett-Teller (BET) method was used to calculate specific surface area of the electrocatalyst and the total pore volume and the surface was examined by V-t method. Discrete-Fourier-Transform (DFT) method was applied to measure the pore size distribution (PSD). The samples were degassed for twelve hours at $200{ }^{\circ} \mathrm{C}$ under vacuum. To monitor weight changes with temperature changes thermogravimetric analysis (TG/DTA) was carried out by TA instruments (SDT Q600) under argon or air flow at a heating rate of $5{ }^{\circ} \mathrm{C} \mathrm{min}^{-1}$ from room temperature to $900{ }^{\circ} \mathrm{C}$. Raman spectrum was recorded by Raman spectrophotometer (Renishaw Raman system, inVia Reflex) with an excitation wavelength of $532 \mathrm{~nm}$ for the $20 \mathrm{~mW}$ air cooled argon ion 
laser source. The power of laser positioned at the sample was $4.0 \mathrm{~mW}$ with diameter 1 $\mathrm{mm}$. Data acquisition time was set to $10 \mathrm{~s}$.

\section{Results and Discussion}
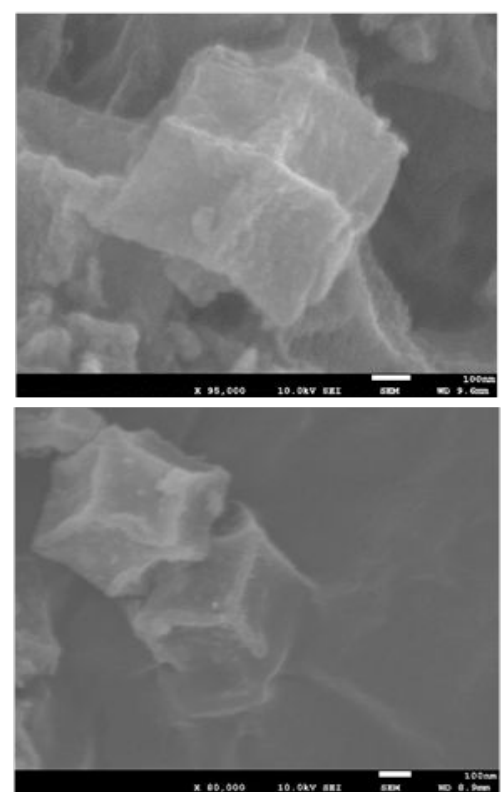

Figure/ S1. SEM images of Co@NC

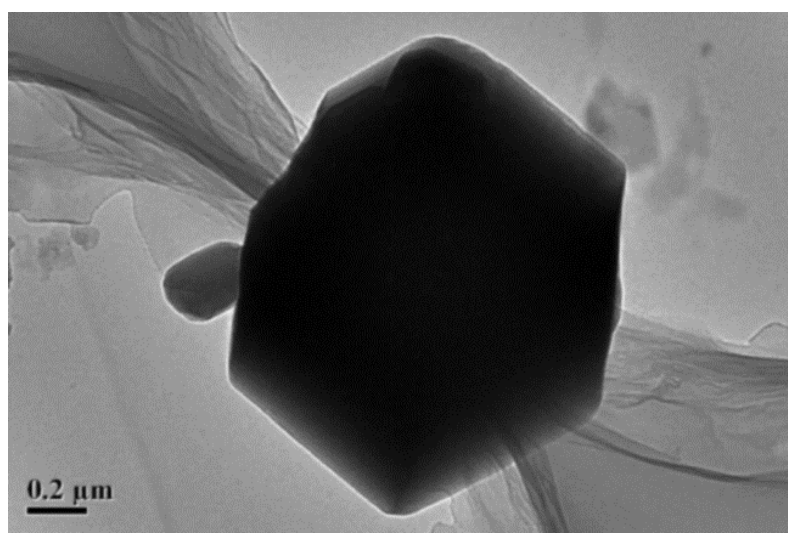

Figure S2. TEM image of NiSAs@ACNTFs before controlled pyrolysis. 


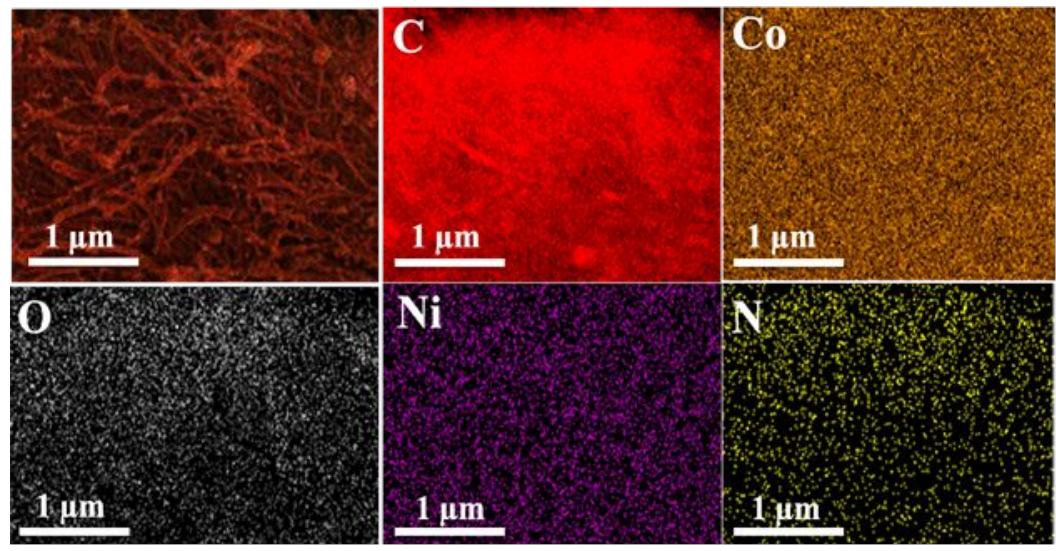

Figure S3. EDS mapping of NiSAs@ACNTFs

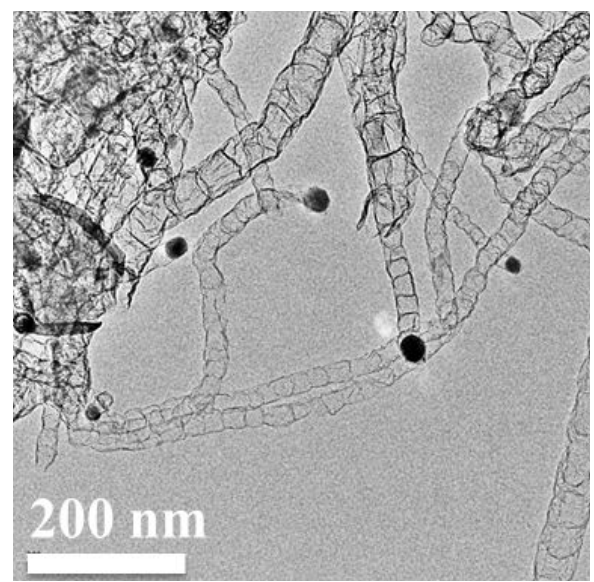

Figure S4. TEM image of NiSAs@ACNTFs after controlled pyrolysis.

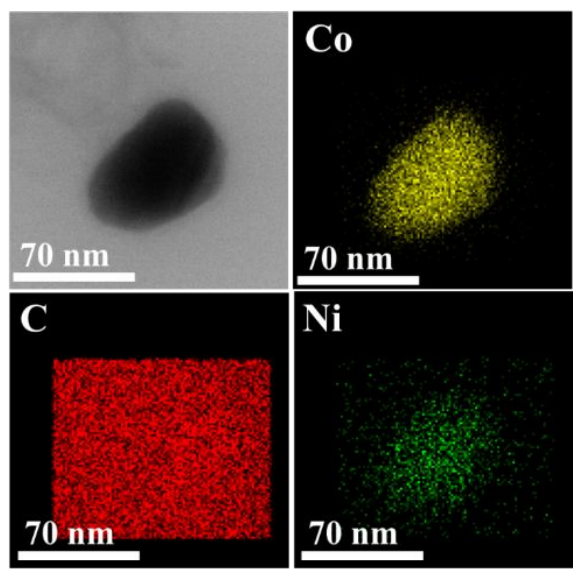

Figure S5. HRTEM mapping of NiSAs@ACNTFs at apex of nanotube. 


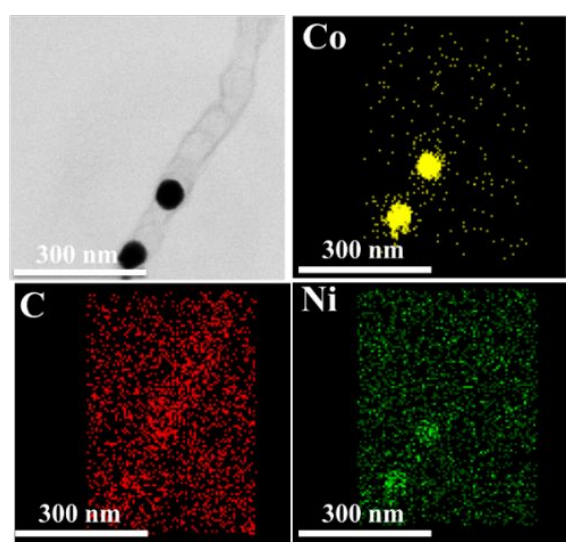

Figure S6. HRTEM mapping of NiSAs@ACNTFs nanotube.

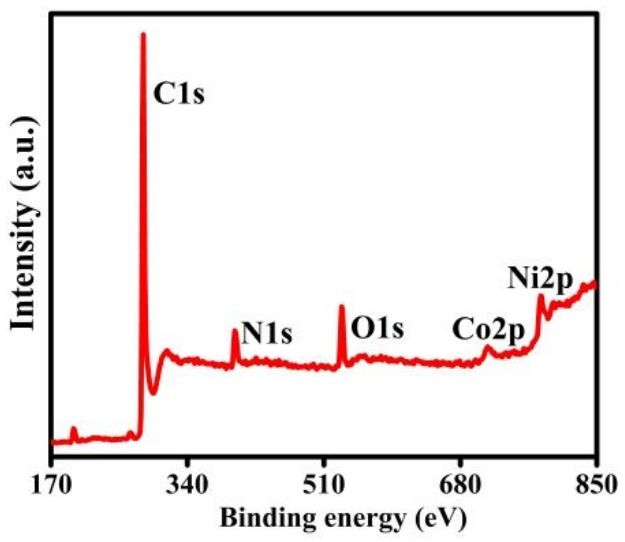

Figure S7. XPS survey of NiSAs@ACNTFs.
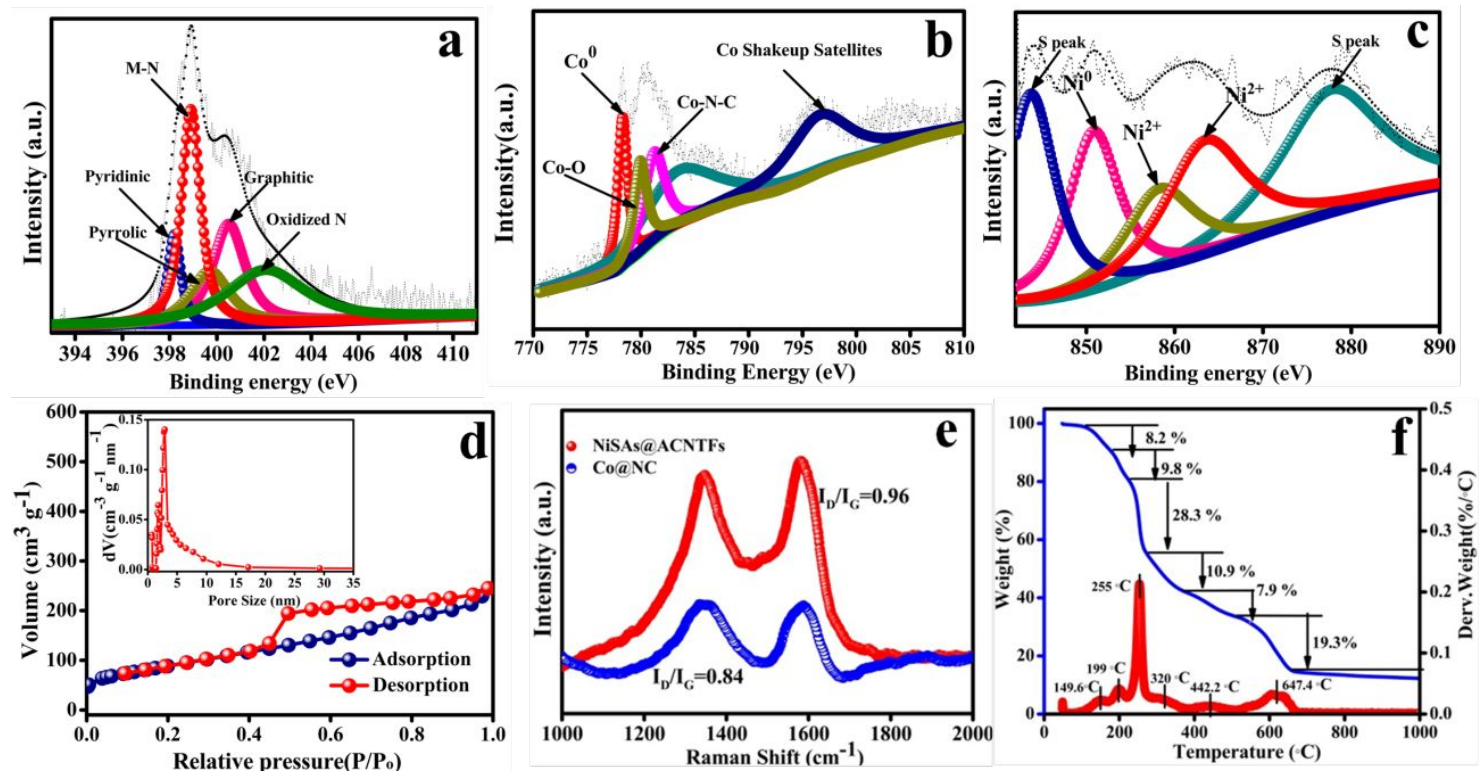

Figure S8. a) high resolution XPS spectrum of N1S (b) high resolution XPS spectrum of Co $2 p$ (c) high resolution XPS spectrum of Ni2p (d) N2 adsorption-desorption isotherm (inset) pores size distribution in NiSAs@ACNTFs (e) Raman analysis of Co@NC and NiSAs@ACNTFs (f) Thermogravemtric profile of NiSAs@ACNTFs. 


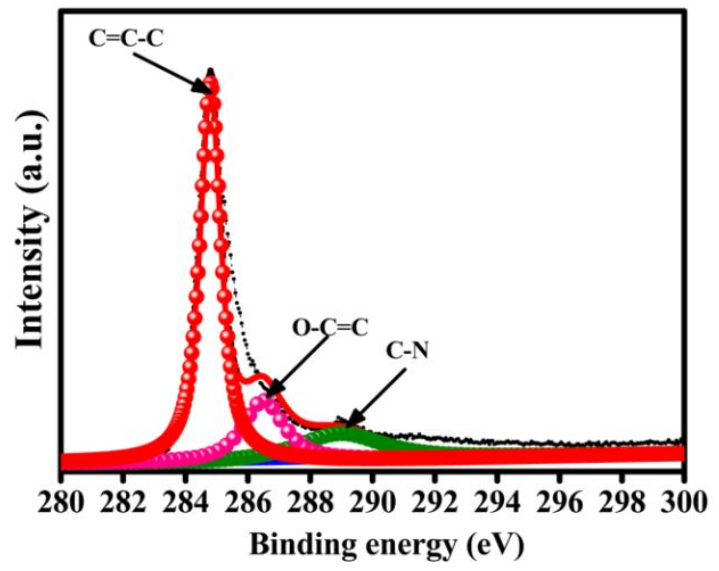

Figure S9. High resolution XPS survey of C1s of NiSAs@ACNTFs

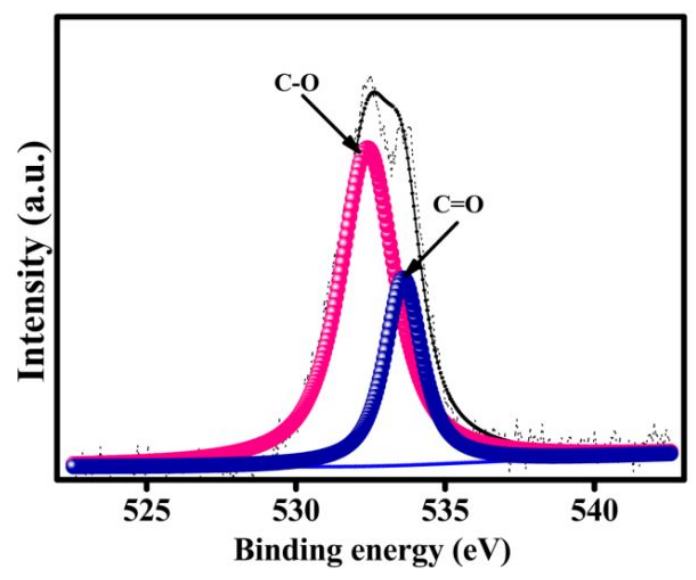

Figure S10. High resolution XPS survey of O1s of NiSAs@ACNTFs.

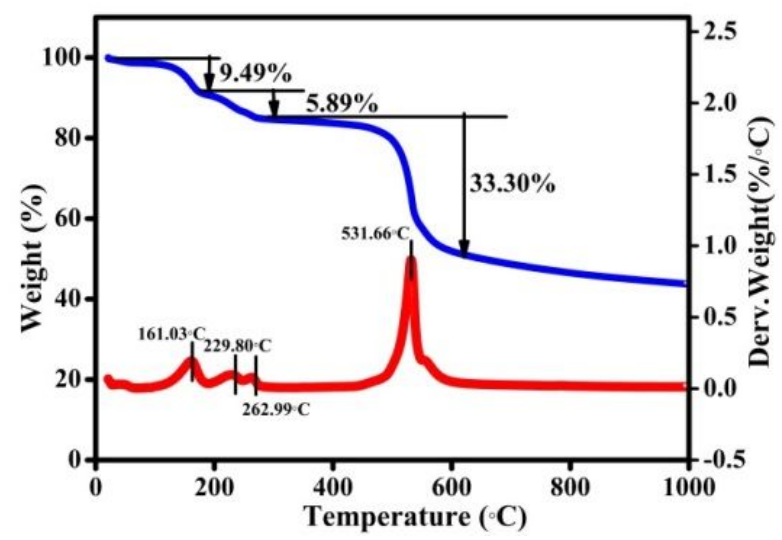

Figure S11. Thermogravimetric profile of DCD 


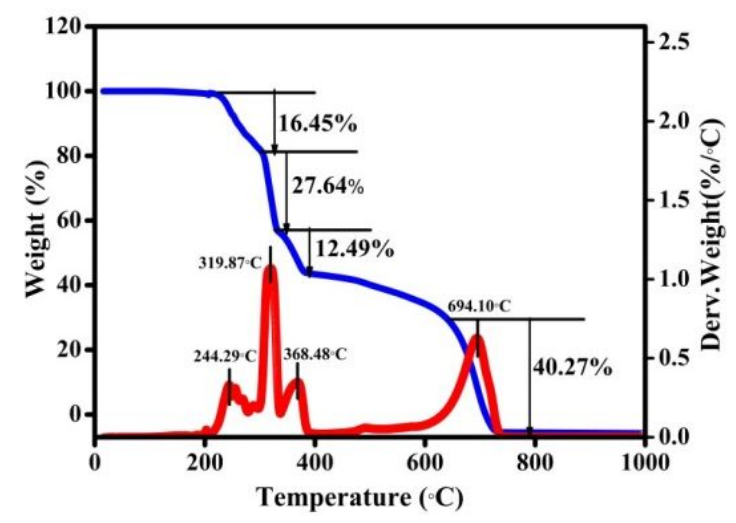

Figure S12. Thermogravimetric profile of $\mathrm{Co} @ \mathrm{NC}$

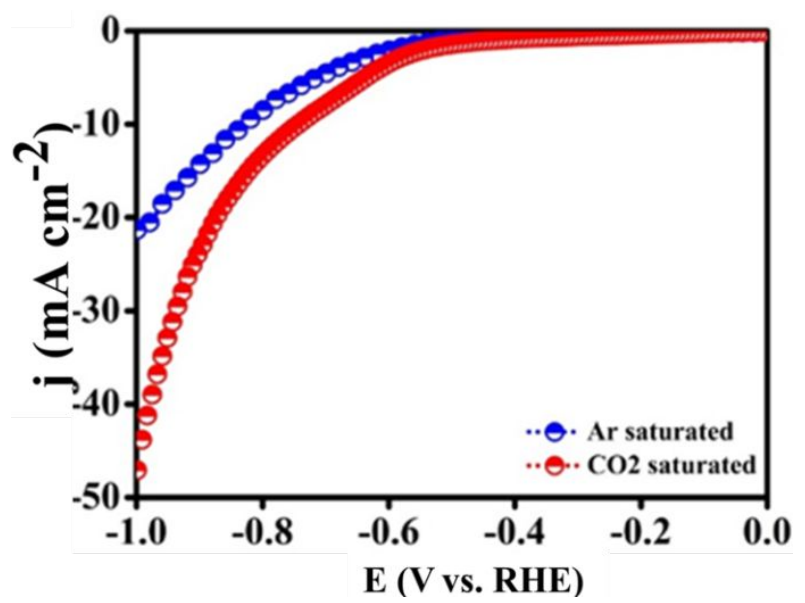

Figure S13. LSV curves of NiSAs@ACNTFs for $\mathrm{CO}_{2} \mathrm{RR}$ in Ar saturated and $\mathrm{CO}_{2}$ saturated $0.5 \mathrm{M} \mathrm{KHCO}_{3}$

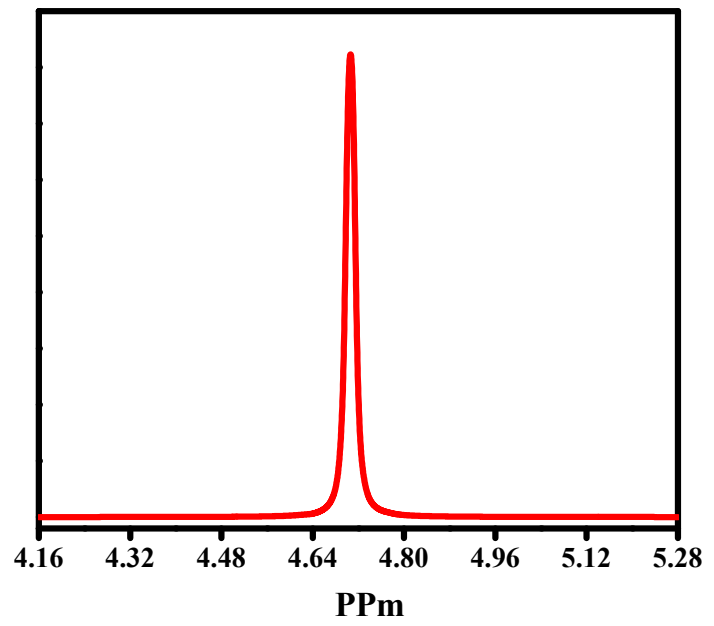

Figure S14. $\mathrm{H}^{1} \mathrm{NMR}$ of electrolyte after electrochemical $\mathrm{CO}_{2}$ reduction showing no other by products are formed except $\mathrm{CO}$. 


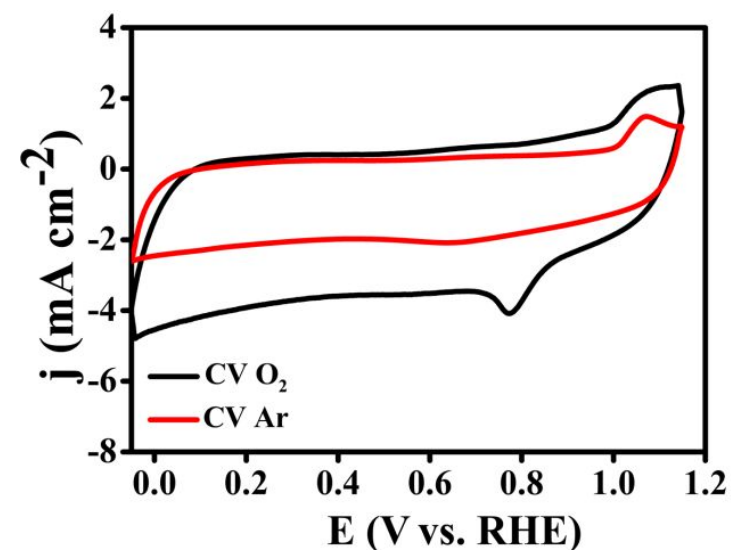

Figure S15. Ar and $\mathrm{O}_{2}$ saturated cyclic voltamogramms of NiSAs@ACNTFs in 0.1M aqueous $\mathrm{KOH}$ at scan rate of $10 \mathrm{mV} / \mathrm{s}$

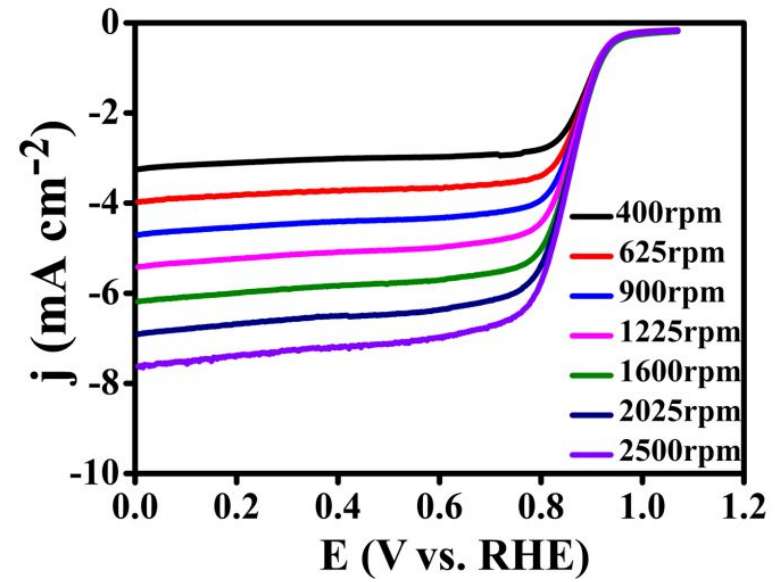

Figure S16. LSV curves of NiSAs@ACNTFs at varying rotational speeds with a scan rate of $10 \mathrm{mV} / \mathrm{s}$.

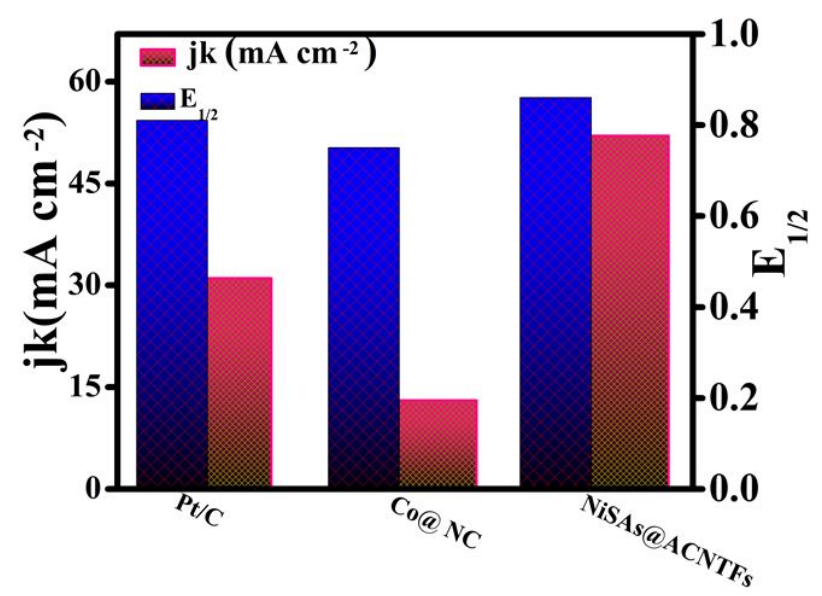

Figure S17. LSV curves of NiSAs@ACNTFs at varying rotational speeds with a scan rate of $10 \mathrm{mV} / \mathrm{s}$. 


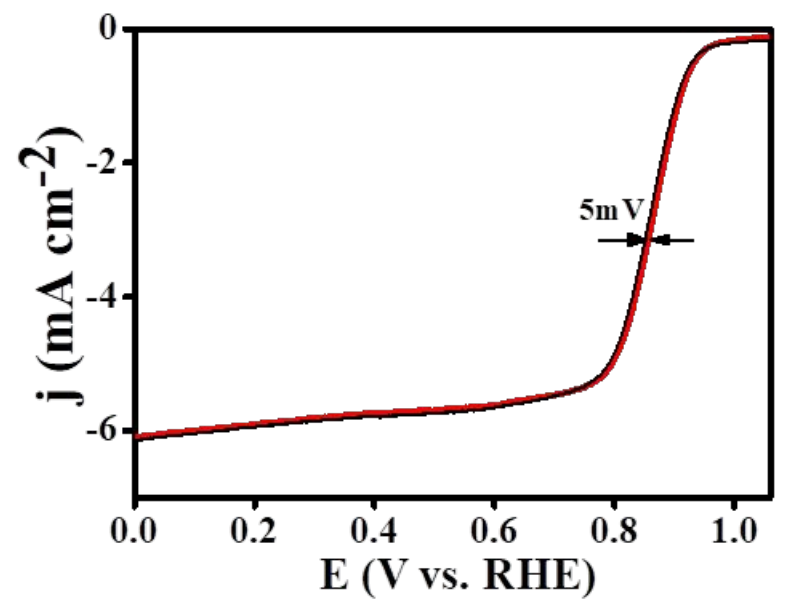

Figure S18. LSV curves of NiSAs@ACNTFs at rotational speed of 1600 rpm with a scan rate of $10 \mathrm{mV} / \mathrm{s}$ before and after continuous $5000 \mathrm{CV}$ cycles.

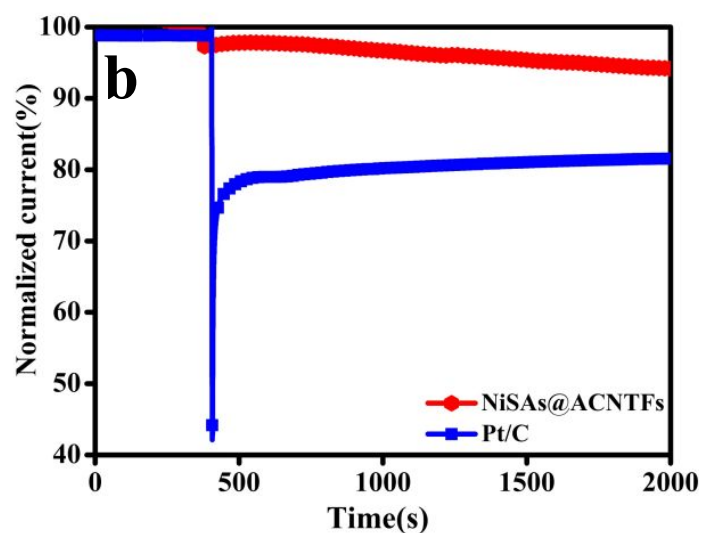

Figure S19. Chronoamperometric curves in an $\mathrm{O}_{2}$ saturated electrolyte with addition of $3 \mathrm{M}$ methanol.

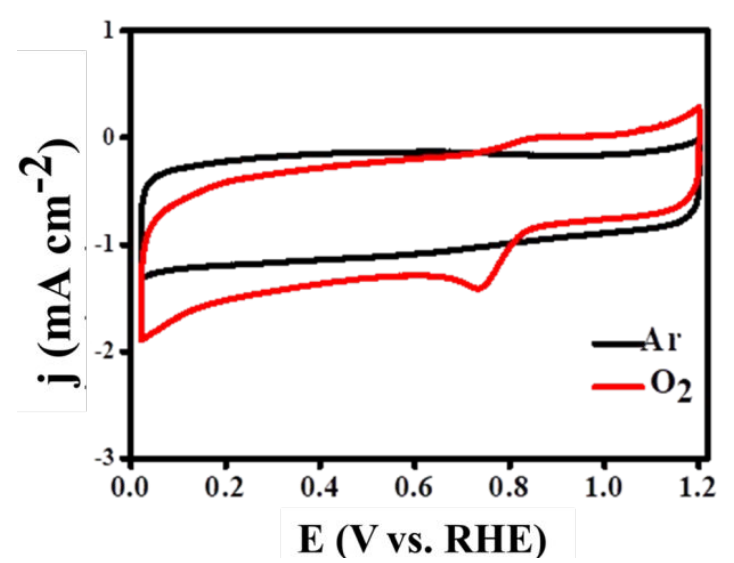

Figure S20. Ar and $\mathrm{O}_{2}$ saturated cyclic voltammograms of NiSAs@ACNTFs at scan rate of $10 \mathrm{mV} / \mathrm{s}$ in $0.1 \mathrm{M} \mathrm{HClO}_{4}$ 


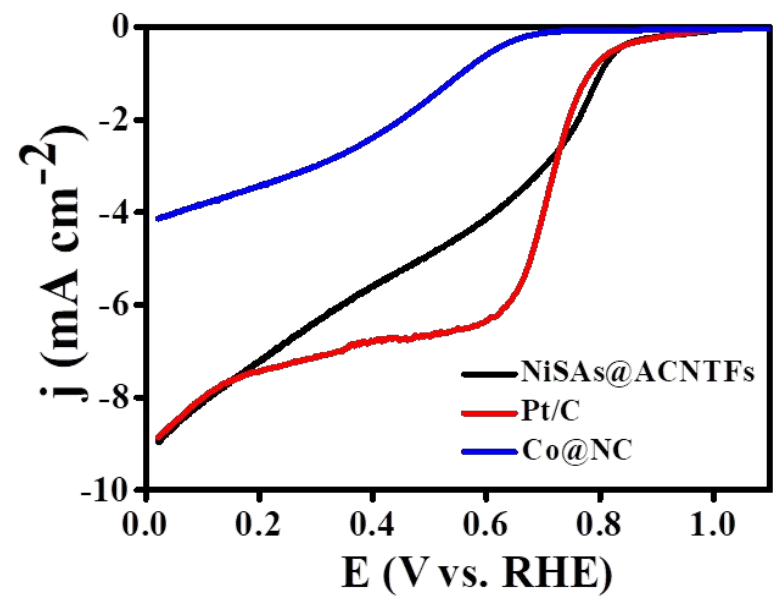

Figure S21. LSV curves of NiSAs@ACNTFs, Co@NC, and Pt/C at a rotational speed of $1600 \mathrm{rpm}$ and scan rate of $10 \mathrm{mV} / \mathrm{s}$ in $0.1 \mathrm{M} \mathrm{HClO}_{4}$

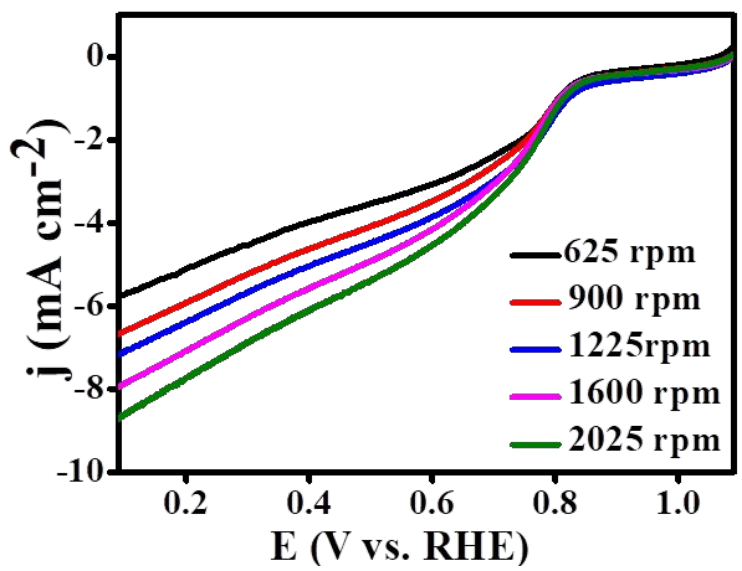

Figure S22. LSV curves of NiSAs@ACNTFs at varying rotational speeds with a scan rate of $10 \mathrm{mV} / \mathrm{s}$ in $0.1 \mathrm{M} \mathrm{HClO}_{4}$

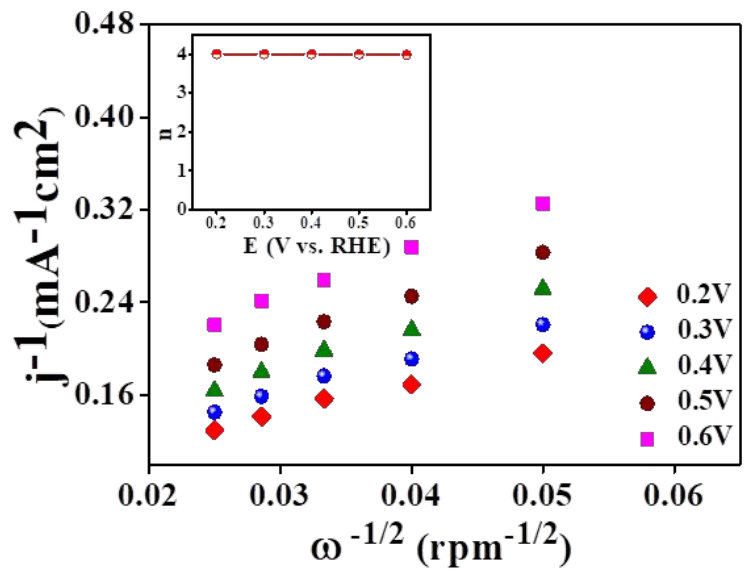

Figure S23. Koutecky-Levich plots of NiSAs@ACNTFs obtained at different potentials (inset) electron-transfer number for NiSAs@ACNTFs calculated from K-L plots at different potentials $(0.2 \mathrm{~V}-0.6 \mathrm{~V})$ in $0.1 \mathrm{M} \mathrm{HClO}_{4}$ 


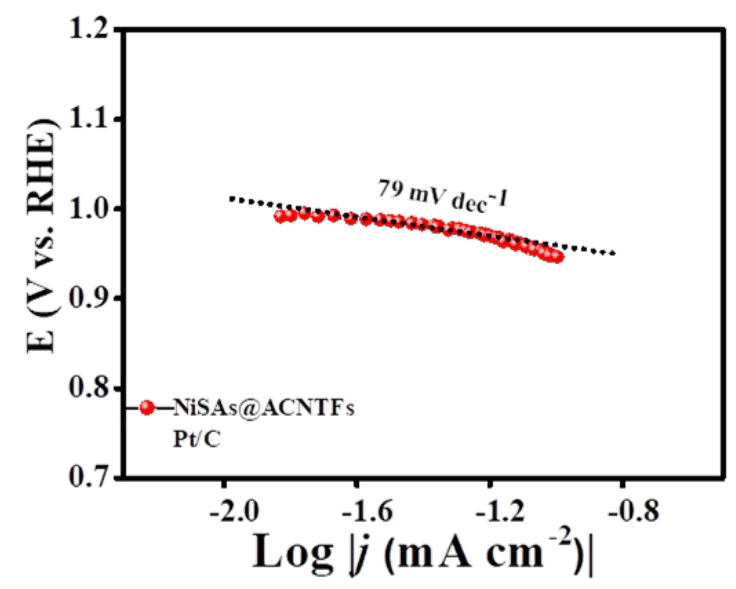

Figure S24. Tafel plots corresponding to NiSAs@ACNTFs Co@NC, and Pt/C.

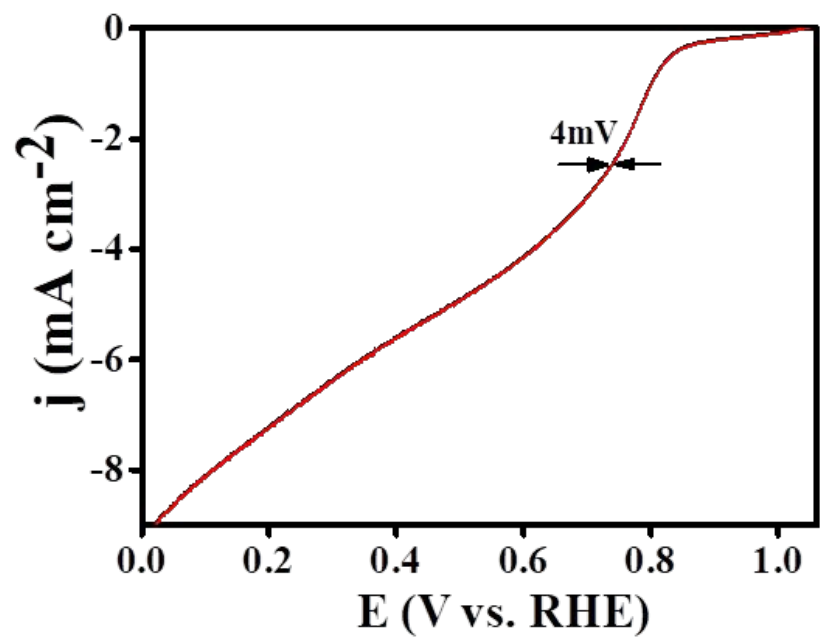

Figure S25. LSV curves of NiSAs@ACNTFs at rotational speed of 1600 rpm with a scan rate of $10 \mathrm{mV} / \mathrm{s}$ before and after continuous $1500 \mathrm{CV}$ cycles $(100 \mathrm{mV} / \mathrm{s})$ in $0.1 \mathrm{M}$ $\mathrm{HClO}_{4}$

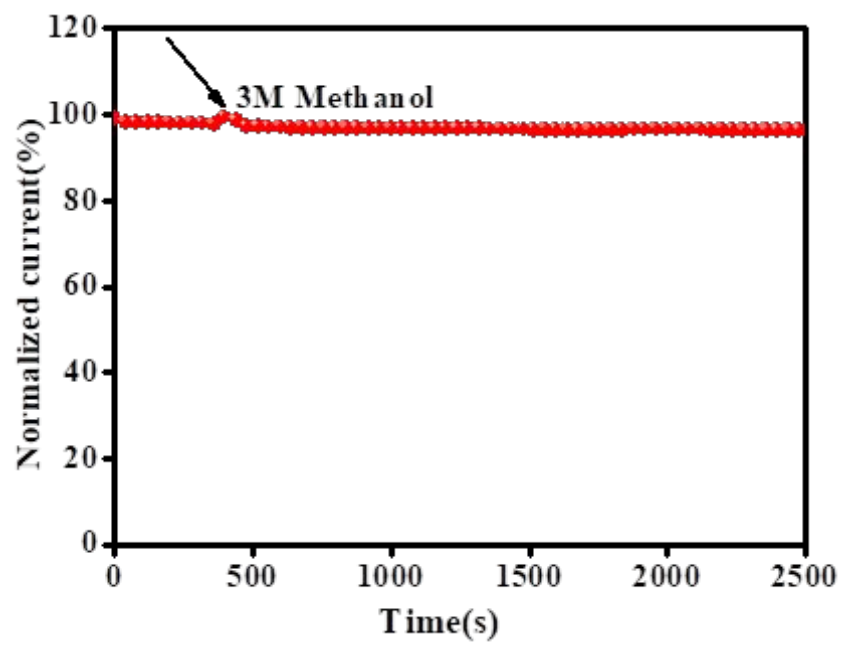

Figure S26. Chronoamperometric curves in an $\mathrm{O}_{2}$ saturated electrolyte with addition of $3 \mathrm{M}$ methanol. 


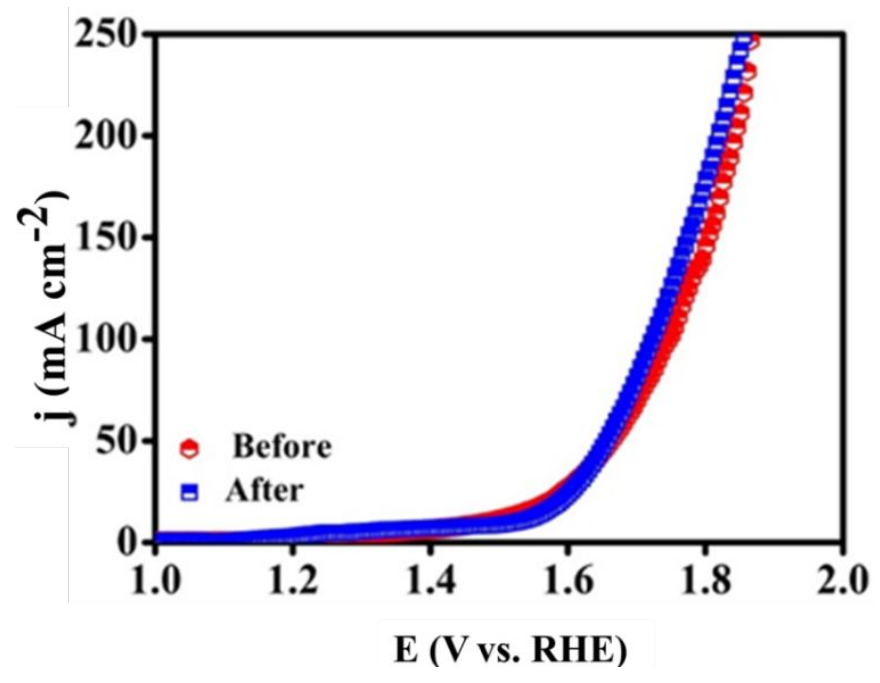

Figure S27. LSV curves of NiSAs@ACNTFs for OER with a scan rate of $10 \mathrm{mV} / \mathrm{s}$ before and after electrolysis.

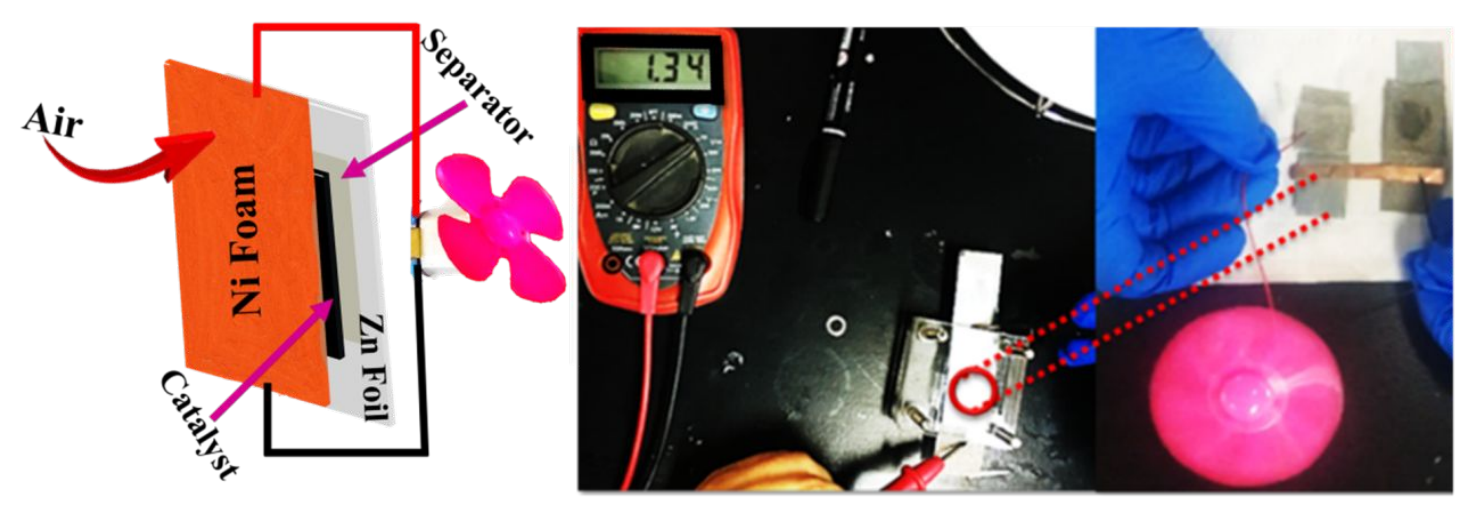

Figure S28. Schematic fabrication of $\mathrm{Zn}$ air battery and digital photograph of fabricated zinc-air battery with open circuit voltage running a small motor fan.

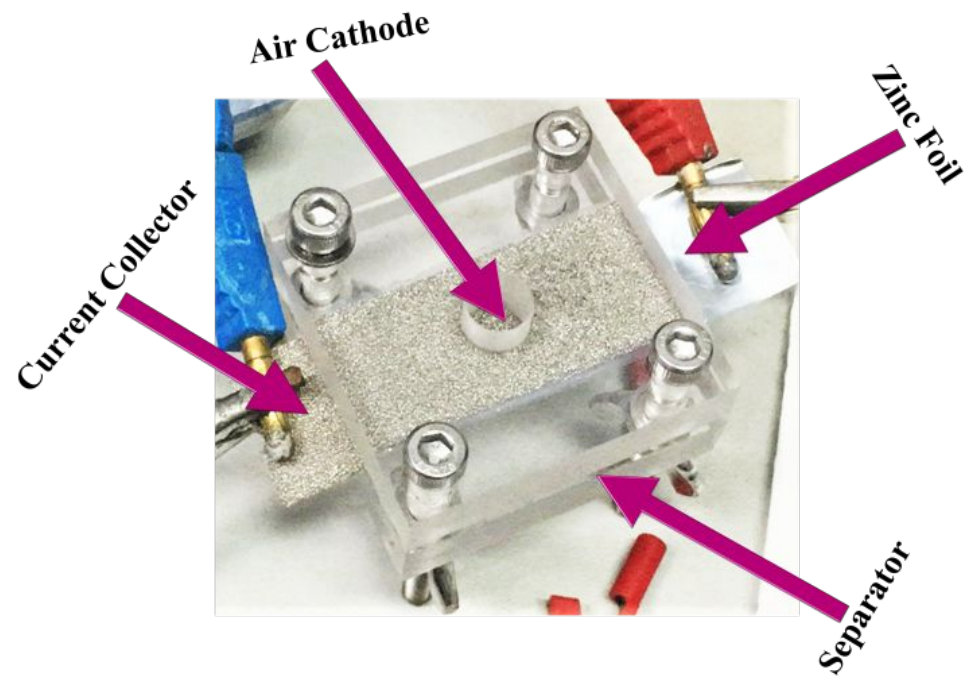

Figure S29. Fabrication of all solid state zinc air battery 

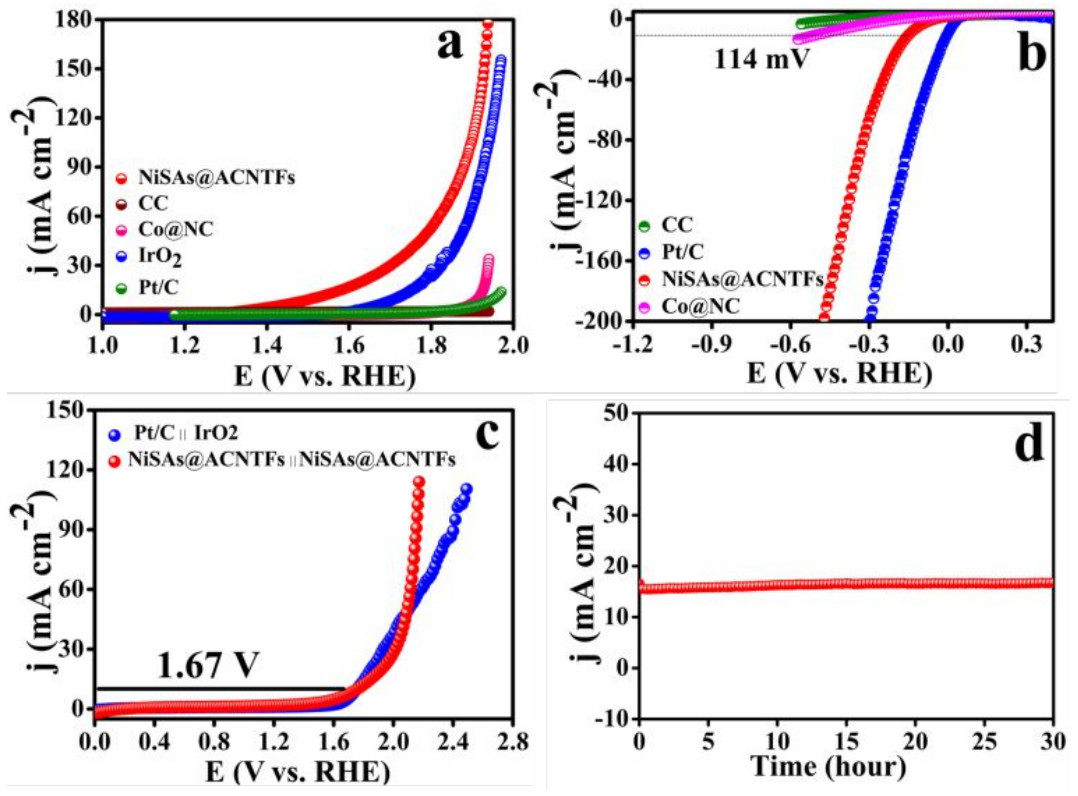

Figure S30. Overall water splitting reactions by catalyst at $\mathrm{pH}=7$. (a) OER polarization curves of NiSAs@ACNTFs, Co@NC, Pt/C, IrO ${ }_{2}$ and $\mathrm{CC}$ at a scan rate of $10 \mathrm{mV} / \mathrm{s}$ in $1 \mathrm{M}$ PBS. (b) HER polarization curves of NiSAs@ACNTFs, Co@NC, Pt/C, and CC at a scan rate of 10 mV/s in 1M PBS. (c) LSV curves for overall water splitting by NiSAs@ACNTFs \| NiSAs@ACNTFs and Pt/C \| IrO $\mathrm{Ir}_{2}$ at scan rate of 10 mV/s in 1M PBS. (d) Long term stability NiSAs@ACNTFs \| NiSAs@ACNTFs at potential corresponding to current density of $10 \mathrm{~mA} / \mathrm{cm}^{2}$ for overall water splitting in $1 \mathrm{M}$ PBS.

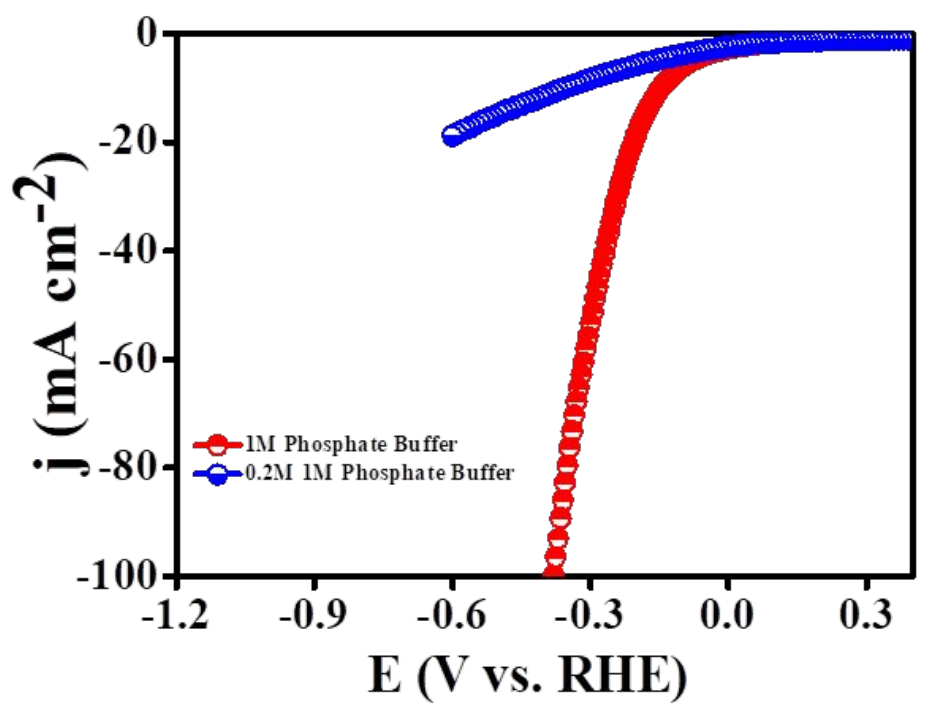

Figure S31. HER polarization curves of NiSAs@ACNTFs a scan rate of $10 \mathrm{mV} / \mathrm{s}$ in $0.2 \mathrm{M}, 0.5 \mathrm{M}$ and $1 \mathrm{M}$ PBS 


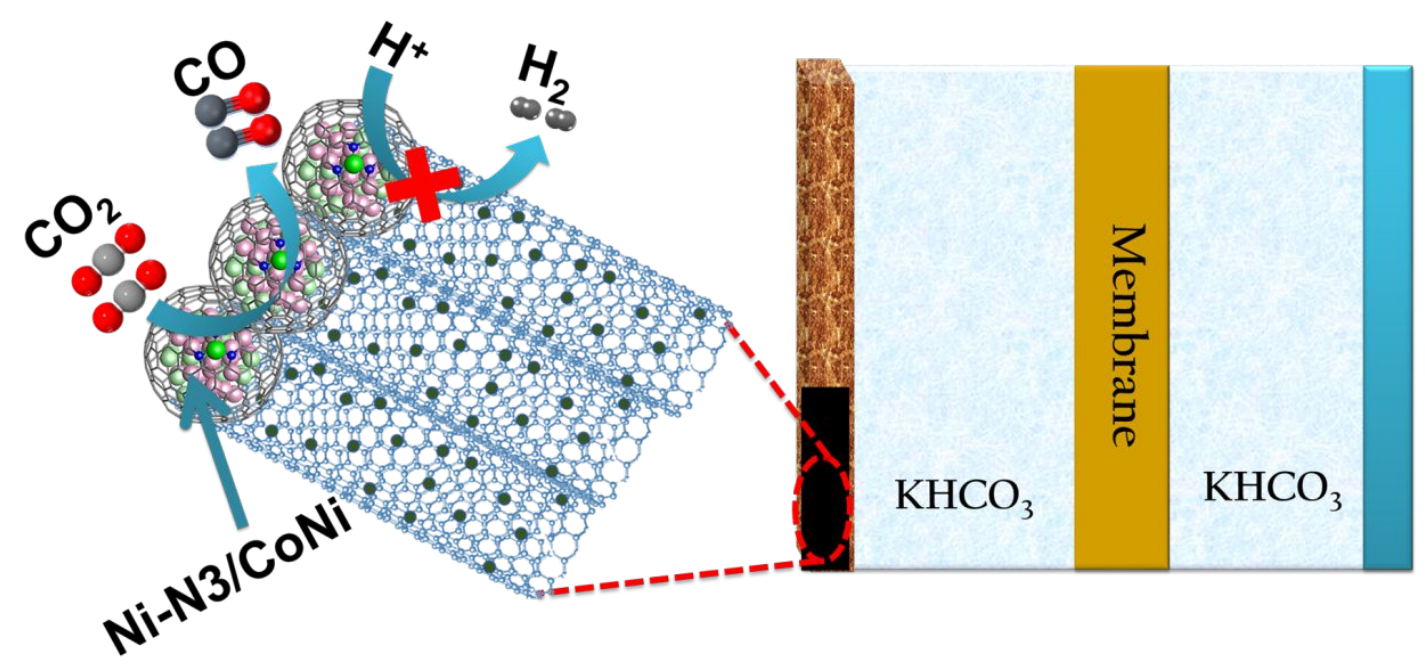

Scheme S1. Competition between $\mathrm{CO}_{2} \mathrm{RR}$ and HER in $\mathrm{KHCO}_{3} \cdot \mathrm{Ni}-\mathrm{N} 3 / \mathrm{CoNi}$ blocks the adsorption of proton on the catalyst.

Video S1: Practical demonstration of Zn- air battery by a small motor fan. 


\begin{tabular}{|c|c|c|c|c|c|c|c|c|c|c|c|c|c|}
\hline \multirow[t]{2}{*}{ Materials } & \multicolumn{2}{|c|}{ ORR } & \multicolumn{2}{|c|}{$\begin{array}{c}\text { OER } \eta_{10 \mathrm{Vs}, \text { RHE }} \\
(\mathrm{mV})\end{array}$} & \multirow{2}{*}{$\begin{array}{c}\text { Bifunctional } \\
\text { Electrocatalysis } \\
\Delta E / V\left(E_{\mathrm{OER}^{-}}\right. \\
\left.E_{\mathrm{ORR}}\right)\end{array}$} & \multicolumn{2}{|c|}{$\begin{array}{c}\text { HER } \\
\eta_{10 \mathrm{Vs}, \mathrm{RHE}}\end{array}$} & \multicolumn{2}{|c|}{$\begin{array}{l}\text { Water Splitting } \\
\mathbf{E}_{\text {Cell }}\end{array}$} & \multicolumn{2}{|c|}{$\mathrm{CO}_{2} \mathrm{RR}$} & \multirow{2}{*}{$\begin{array}{c}\begin{array}{c}\text { Zn air } \\
\text { battery }\end{array} \\
\text { OCV }\end{array}$} & \multirow[t]{2}{*}{ References } \\
\hline & $\begin{array}{c}\mathbf{E}_{\text {Onset }} \\
\text { Vs. }{ }^{*}{ }^{*}\end{array}$ & $\mathrm{E}_{1 / 2}$ & Alkaline $\uparrow$ & Neutral $\star$ & & $\begin{array}{c}\text { Alkaline } \\
t\end{array}$ & Neutral $\star$ & $\underset{\leftarrow}{\text { Alkaline }}$ & Neutral $\star$ & $\begin{array}{c}\text { FE } \\
\text { CO }^{\diamond}\end{array}$ & $\begin{array}{c}\text { Potential V } \\
\text { Vs. RHE }\end{array}$ & & \\
\hline $\mathrm{Pt} / \mathrm{C}(20 \mathrm{wt} \%)$ & 0.96 & 0.82 & 630 & 710 & 1.01 & 20 & 27 & -- & -- & --- & --- & -- & This work \\
\hline Co@NC & 0.91 & 0.8 & 660 & 680 & 1.09 & 340 & 560 & & & & & -- & This work \\
\hline $\mathrm{Pt} / \mathrm{C}(20 \mathrm{wt} \%) \| \mathrm{IrO}_{2}$ & -- & -- & -- & -- & -- & -- & -- & 1.70 & 1.72 & -- & -- & -- & This work \\
\hline NiSAs@ACNTFs & 0.98 & 0.86 & 250 & 315 & 0.62 & 49 & 114 & 1.57 & 1.67 & 99 & -0.9 & 1.34 & This work \\
\hline CoNC700 & 0.96 & -- & -- & -- & -- & -- & -- & -- & -- & -- & -- & -- & S1 \\
\hline $\mathrm{Ni}-\mathrm{MnO} / \mathrm{rGO}$ & 0.94 & 0.78 & 370 & -- & 0.82 & -- & -- & -- & -- & -- & -- & -- & S2 \\
\hline $15 \%$ PANI/ZIF-67 & 0.85 & 0.75 & 330 & -- & 0.83 & $350^{\bullet}$ & -- & --- & -- & --- & -- & -- & S3 \\
\hline NiCoP/CNF 900 & - & 0.82 & 268 & -- & - & 130 & -- & 1.65 & -- & -- & -- & -- & S4 \\
\hline Co@NCNT HMS & 0.98 & 0.857 & 317 & -- & 0.681 & 169 & -- & -- & -- & --- & -- & -- & S5 \\
\hline NS/ rGO-Co4 & 0.97 & 0.820 & 265 & --- & 0.70 & 150 & --- & 1.72 & -- & --- & --- & -- & S6 \\
\hline $\begin{array}{c}\text { NiFe LDH@ } \\
\text { NiCoP/NF }\end{array}$ & --- & --- & 220 & --- & --- & 120 & -- & 1.57 & -- & --- & -- & -- & S7 \\
\hline $\begin{array}{c}\mathrm{Co}(\mathrm{OH})_{2}-\mathrm{Au}- \\
\mathrm{Ni}(\mathrm{OH})_{2}\end{array}$ & -- & --- & $340^{\dagger}$ & -- & -- & $200^{+}$ & -- & $1.75^{\dagger}$ & -- & -- & -- & -- & S8 \\
\hline $\mathrm{CoO} / \mathrm{Co}_{4} \mathrm{~N}$ & -- & -- & -- & 398 & +- & -- & 145 & -- & 1.79 & -- & --- & -- & S9 \\
\hline $\mathrm{NiAl}_{\hat{\delta}} \mathbf{P}$ & -- & -- & 242 & 400 & -- & 80 & 100 & 1.55 & 1.73 & --- & -- & -- & S10 \\
\hline NCMT-1000 (3D) & 1.05 & -- & 290 & -- & 0.63 & -- & -- & -- & -- & --- & -- & -- & S11 \\
\hline A-Ni-NSG ${ }^{\diamond}$ & --- & -- & -- & --- & --- & -- & -- & -- & -- & 97 & -0.5 & -- & S12 \\
\hline NSHCF900 & -- & --- & -- & -- & -- & -- & -- & -- & -- & 94 & -0.7 & -- & S13 \\
\hline $\mathrm{Mo}-\mathrm{N} / \mathrm{C} @ \mathrm{MoS}_{2}$ & 0.90 & 0.81 & 390 & +- & +- & 117 & -- & -- & -- & -- & -- & 1.34 & S14 \\
\hline $\mathrm{o}-\mathrm{CC}-\mathrm{H}_{2}$ & -- & -- & 388 & -- & -- & -- & -- & -- & -- & --- & -- & 1.258 & S15 \\
\hline $\mathrm{Co}-\mathrm{N} x / \mathrm{C}$ NRA & $\overline{---}$ & 0.877 & 300 & -- & --- & -- & -- & -- & -- & --- & -- & 1.265 & S16 \\
\hline
\end{tabular}

Table S1. Summary of the electrocatalytic performances of recent tri /bi /

multi-functional electrocatalysts in recent literature

\section{References}


(1) Wan, G.; Yu, P.; Chen, H.; Wen, J.; Sun, C.; Zhou, H.; Zhang, N.; Li, Q.; Zhao, W.; Xie, B.; Li, T.; Shi, J. Engineering Single-Atom Cobalt Catalysts toward Improved Electrocatalysis. Small 2018, 14, 1704319-1704325. https://doi.org/10.1002/smll.201704319.

(2) Khalid, M.; Honorato, A. M. B.; Varela, H.; Dai, L. Nano Energy Multifunctional Electrocatalysts Derived from Conducting Polymer and Metal Organic Framework Complexes. Nano Energy 2018, 45 (December 2017), 127-135. https://doi.org/10.1016/j.nanoen.2017.12.045.

(3) Fu, G.; Yan, X.; Chen, Y.; Xu, L.; Sun, D.; Lee, J. Boosting Bifunctional Oxygen Electrocatalysis with 3D Graphene Aerogel-Supported Ni / MnO Particles. Adv. Mater. 2018, 30, 1704609-1704618. https://doi.org/10.1002/adma.201704609.

(4) Surendran, S.; Shanmugapriya, S.; Sivanantham, A.; Shanmugam, S.; Kalai

Selvan, R. Electrospun Carbon Nanofibers Encapsulated with NiCoP: A Multifunctional Electrode for Supercapattery and Oxygen Reduction, Oxygen Evolution, and Hydrogen Evolution Reactions. Adv. Energy Mater. 2018, 8 (20), 1-18. https://doi.org/10.1002/aenm.201800555.

(5) Zhang, G. Hierarchical 3D Macrosheets Composed of Interconnected in Situ Cobalt Catalyzed Nitrogen Doped Carbon Nanotubes as Superior Bifunctional Oxygen Electrocatalysts for Rechargeable $\mathrm{Zn}$ - Air Batteries †. J. Mater. Chem. 2018, 6, 15523-15529. https://doi.org/10.1039/c8ta06057f. 
(6) Wang, N.; Li, L.; Zhao, D.; Kang, X.; Tang, Z.; Chen, S. Graphene Composites with Cobalt Sulfide : Efficient Trifunctional Electrocatalysts for Oxygen Reversible Catalysis and Hydrogen Production in the Same Electrolyte. Small 2017, 1-10. https://doi.org/10.1002/smll.201701025.

(7) Zhang, H.; Li, X.; Hähnel, A.; Naumann, V.; Lin, C.; Azimi, S.; Schweizer, S. L.; Maijenburg, A. W.; Wehrspohn, R. B. Bifunctional Heterostructure Assembly of NiFe LDH Nanosheets on NiCoP Nanowires for Highly Efficient and Stable Overall Water Splitting. 2018, 1706847, 1-10. https://doi.org/10.1002/adfm.201706847.

(8) Sultana, U. K.; Riches, J. D.; Mullane, A. P. O. Gold Doping in a Layered Co-Ni Hydroxide System via Galvanic Replacement for Overall Electrochemical Water Splitting. Adv. Funct. Mater. 2018, 1804361, 1-8. https://doi.org/10.1002/adfm.201804361.

(9) Online, V. A.; Li, R.; Hu, P.; Miao, M.; Li, Y.; Jiang, X.; Wu, Q.; Meng, Z.; Hu, Z.; Bando, Y.; Wang, X. CoO-Modi Fi Ed Co $4 \mathrm{~N}$ as a Heterostructured Electrocatalyst for Highly efficient Overall Water Splitting in Neutral Media †. J. Mater. Chem. A 2018, 6, 24767-24772. https://doi.org/10.1039/c8ta08519f.

(10) Qinghua, S. Showcasing a Study on the Novel Structure of a 3D Metal- As Featured In : J. Mater. Chem. A 2018, 6, 9420-9427. https://doi.org/10.1039/c8ta01662c.

(11) Li, J. C.; Hou, P. X.; Zhao, S. Y.; Liu, C.; Tang, D. M.; Cheng, M.; Zhang, F.; Cheng, H. M. A 3D Bi-Functional Porous N-Doped Carbon Microtube Sponge 
Electrocatalyst for Oxygen Reduction and Oxygen Evolution Reactions. Energy Environ. Sci. 2016, 9 (10), 3079-3084. https://doi.org/10.1039/c6ee02169g.

(12) Yang, H. Bin; Hung, S.; Liu, S.; Yuan, K.; Miao, S.; Zhang, L.; Huang, X.; Wang, H.; Cai, W.; Chen, R.; Gao, J.; Yang, X.; Chen, W. Atomically Dispersed Ni(i) as the Active Site for Electrochemical CO2 Reduction. Nat. Energy 2018, 3 (February), 140-147. https://doi.org/10.1038/s41560-017-0078-8.

(13) Yang, H.; Wu, Y.; Lin, Q.; Fan, L.; Chai, X.; Zhang, Q.; Liu, J.; He, C.; Lin, Z. Communications Electrocatalysis Very Important Paper Composition Tailoring via $\mathrm{N}$ and S Co-Doping and Structure Tuning by Constructing Hierarchical Pores :

Metal-Free Catalysts for High- Performance Electrochemical Reduction of CO2 Angewandte. Angew. Chemie - Int. Ed. 2018, 30332, 15476-15480.

https://doi.org/10.1002/anie.201809255.

(14) Amiinu, I. S.; Pu, Z.; Liu, X.; Owusu, K. A.; Gabriela, H.; Monestel, R.; Boakye, F. O.; Zhang, H.; Mu, S. Multifunctional Mo-N / C @ MoS2 Electrocatalysts for HER, OER, ORR, and Zn - Air Batteries. Adv. Funct. Mater. 2017, 27, 1702300-1702310. https://doi.org/10.1002/adfm.201702300.

(15) Wang, H. F.; Tang, C.; Wang, B.; Li, B. Q.; Cui, X.; Zhang, Q. Defect-Rich Carbon Fiber Electrocatalysts with Porous Graphene Skin for Flexible Solid-State Zinc-Air Batteries. Energy Storage Mater. 2018, 15, 124-130. https://doi.org/10.1016/j.ensm.2018.03.022. 
(16) Amiinu, I. S.; Liu, X.; Pu, Z.; Li, W.; Li, Q.; Zhang, J. From 3D ZIF

Nanocrystals to Co - N x / C Nanorod Array Electrocatalysts for ORR, OER, and Zn

- Air Batteries. Adv. Funct. Mater. 2018, 28, 1704638-1704646.

https://doi.org/10.1002/adfm.201704638. 